\title{
Differential Diagnosis of Pancreatic Cyst Tumors
}

\author{
Kashchenko VA ${ }^{1}$, Solonitsyn EG ${ }^{1,2 *}$, Vasyukova EL ${ }^{1}$, Berko $\mathrm{OM}^{2}$ and Bakirov $\mathrm{II}^{3}$ \\ ${ }^{1}$ St. Petersburg State University, Russia \\ ${ }^{2}$ Almazov`s National Medical Research Centre, Russia \\ ${ }^{3}$ Al Imam Abdulrahman Alfaisal Hospital, Riyadh, Kingdom of Saudi Arabia \\ *Corresponding author: Solonitsyn EG, Almazov`s National Medical Research Centre, Russia
}

Submission: 眥 October 15, 2018 ; Published: 海 November 16, 2018

\begin{abstract}
Pancreatic cystic neoplasm is a group of neoplastic changes in the epithelium of the ducts or parenchyma of the pancreas. This is a complex diagnostic problem of modern medicine. With the improvement of diagnostic methods for pancreatic pathology, the frequency of detection of incidental pancreatic cysts has been increased. Some cystic lesions neoplasms are recognized as precursor of pancreatic adenocarcinoma and requires early surgical treatment, or close observation. The article discusses the issues of classification, the malignant potential and the differential diagnosis of pancreatic cysts.
\end{abstract}

Keywords: Pancreatic cyst; Incidental cysts; Incidentaloma, IPMN, MCN, SCN, Pancreatic Pseudocyst; SPN

Abbreviations: US: Abdominal Ultrasound; CT: Computed Tomography; MRI: Magnetic Resonance Imaging; PCNs: Pancreatic Cystic Neoplasm; MCN: Mucinous Cystic Neoplasm; IPMN: Intraductal Papillary Mucinous Neoplasm; SCN: Serous Cystic Neoplasm; SPN: Solid Pseudopapillary Neoplasm; EUS: Endoscopic Ultrasound; CLE: Confocal Laser Endomicroscopy; PET: Positron Emission Tomography

\section{Introduction}

Pancreatic cystic neoplasm is a group of neoplastic changes in the epithelium of the ducts or parenchyma of the pancreas. This is a complex diagnostic problem of modern medicine. With the improvement of diagnostic methods for pancreatic pathology, the frequency of detection of incidental cysts has been increased. A large number of cysts are detected during abdominal ultrasound (US), computed tomography (CT) or magnetic resonance imaging (MRI). Often, examinations are performed on other reasons that do not imply the presence of pancreatic pathology. The tumors revealed in this way are denoted by the term of incidentaloma [1].

Some cystic lesions neoplasms are recognized as precursor of pancreatic adenocarcinoma and requires early surgical treatment, or close observation [2]. So, according to Chernyak V et al. [3] incidental pancreatic cysts detected by CT or MRI studies are associated with an increased risk of mortality in patients younger than 65 years old, and they also have an increased risk of developing adenocarcinoma [3]. Other cysts, such as serous cystic neoplasm, do not have the potential for malignancy. A number of cystic neoplasms initially have signs of malignancy and represent an immediate threat (solid pseudopapillary neoplasm, cystic neuroendocrine neoplasm). Thus, the differential diagnosis of pancreatic cystic neoplasms affects the further management plan of the patient, and consequently, the duration and quality of life of the patient. The difficulties to opt the management of patients with pancreatic cystic neoplasms lie in the fact that the surgery is the only method of radical treatment. It is known that pancreatic surgery itself is a serious risk factor for mortality and can significantly reduce the quality of life of the patients [4-6].

The economic feasibility of such operations is also another difficult issue. There is no doubt that surgery to prevent pancreatic cancer is clinically and economically beneficial. However, the preoperative diagnosis of cystic neoplasm often remains probabilistic and does not guarantee the coincidence of the postoperative diagnosis. On the other hand, the advanced pancreatic adenocarcinoma critically reduces the patient's 5 year survival rate. Close follow up of patient requires the implementation of expensive investigations that significantly increase the cost of such programs. Ideally, the operation should be performed in a patient with a guaranteed prognosis of adenocarcinoma, before its development [7].

\section{Discussion}

Classification and brief description of pancreatic cysts

Basically, all pancreatic cysts can be divided into two large groups [8,9] (Figure 1)

1. Non-Neoplastic

2. Neoplastic

Most non-neoplastic cysts are pancreatic pseudocysts, which are complications of the pancreatitis. On average, about $80 \%$ of all cysts are non-neoplastic. Proportion of neoplastic cysts increases significantly with age $[10,11]$. Neoplastic cysts are 
referred to as pancreatic cystic neoplasm (PCNs). Neoplastic cysts are divided into two groups: mucinous and non-mucinous cysts. Among the mucinous cysts, there are two more groups: mucinous cystic neoplasm (MCN) and intraductal papillary mucinous neoplasm (IPMN). The main representatives of nonmucinous cystic neoplasia's are serous cystic neoplasm (SCN), solid pseudopapillary neoplasm (SPN), as well as the cystic form of neuroendocrine neoplasm. The proportion of cystic neoplasms varies among themselves depending on the population. Thus, in the Western Hemisphere, SCN is 32\% -39\%, MCN - 10\% -40\%, IPMN - $11 \%-33 \%$, SPN - less than $10 \%$. Some other data are shown by researchers from Korea: IPMN - 41\%, MCN - 25.2\%, SPN - 18.3\%, SCN $15.2 \%$, other $-0.3 \%$ [12].

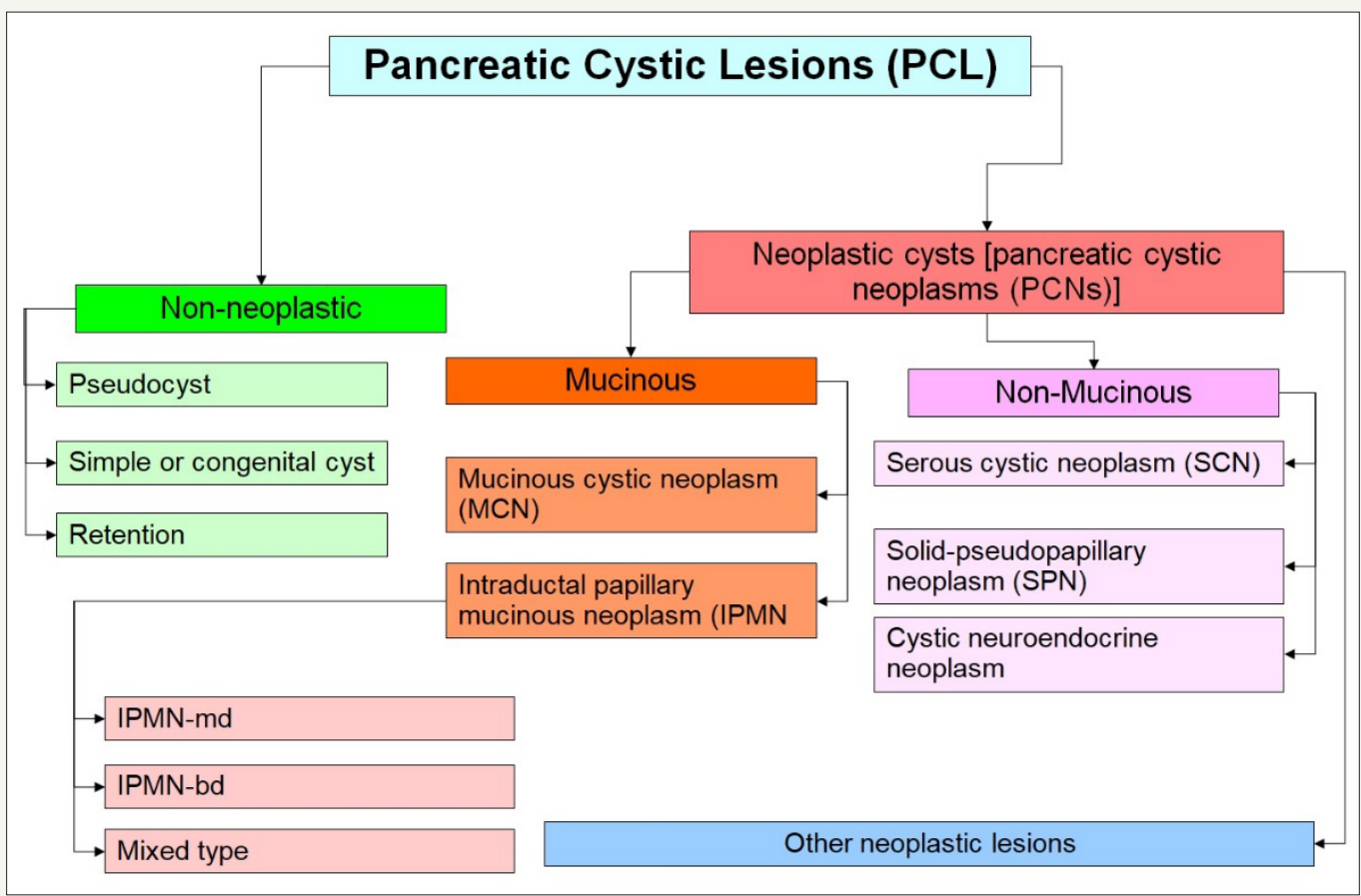

Figure 1: Common schema classification of pancreatic cystic lesions.

\section{Pancreatic pseudocyst}

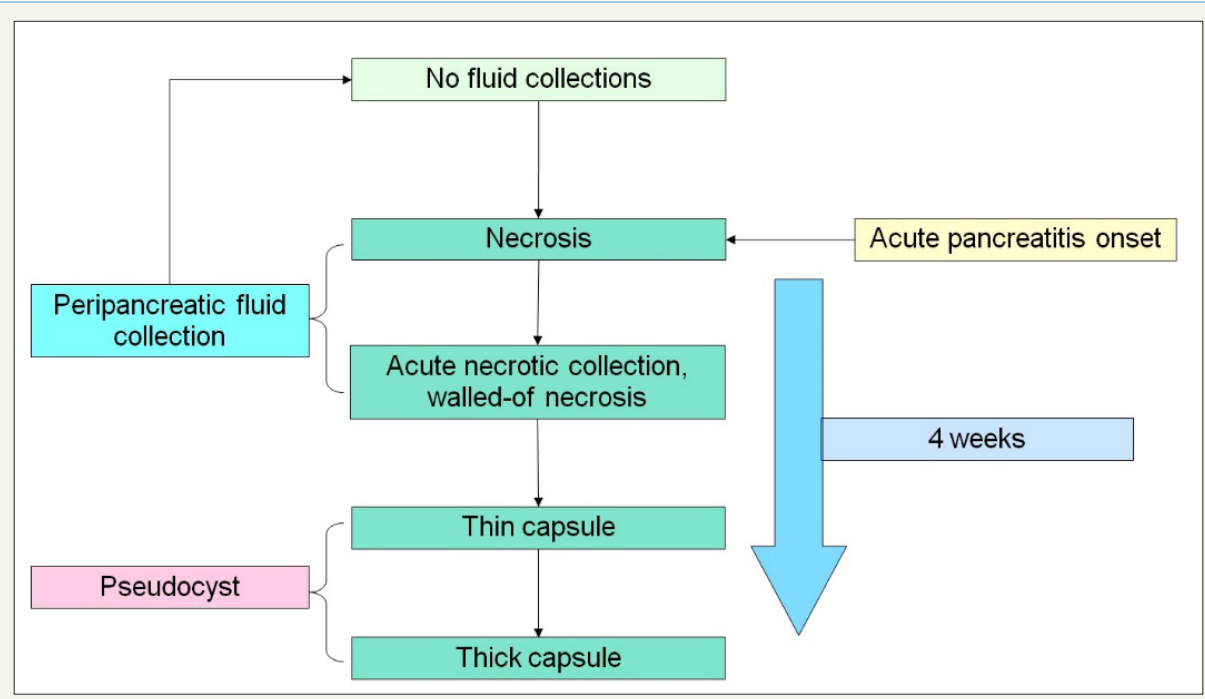

Figure 2: Common schema pseudocist formation.

Pancreatic pseudocysts are an accumulation of inflammatory fluid, which is a complication of the alcoholic, biliary, or other pancreatitis [13]. In addition, pseudocysts can form as a result of complication of surgical treatment and pancreatic injuries [14-16]. The term "pseudocyst" takes into account the fact that this type of cyst does not have an epithelial lining and is not a true cyst [12] During acute pancreatitis or relapse attack of chronic pancreatitis, acute parapancreatic fluid collections are formed [17]. In most studies, develop of pseudocysts is noted within 4 weeks after the onset of the disease (Figure 2). But the time can vary from 3 to 8 
weeks [18-21]. The mechanism for the developing of a pseudocyst is to delimitation the peripancreatic fluid collections and the forming of a fibrous capsule. In this regard, pseudocysts are not incidental finding. In most cases, they are come after an attack of pancreatitis, but in rare cases, the pseudocyst can be formed without the clinical symptoms, on the background of chronic pancreatitis [22].

It is important to distinguish between such concepts as acute peripancreatic fluid collection, acute necrotic collection, walled-off necrosis, pseudocyst and abscess. The definitions of morphological features of acute pancreatitis are given in the Atlanta classification of acute pancreatitis -2012 [23]. Pseudocyst looks like monocystic lesion, usually oval or round-shaped, with a uniform, welldefined fibrous capsule without inner epithelial lining [23,24]. Communication with the pancreatic duct is absent (Figure 3A \& 3B). The pancreas has signs of pancreatitis [25]. Pseudocyst contains of fluid that often transparent or brown, leaking, low viscosity, with high level of amylase and pancreatic enzymes. Sometimes, a small amount of debris can be detected in the lumen of the cyst [25]. In the case of infection of the cyst appear pussy contents. Pseudocyst located more outside the pancreatic parenchyma, in the zone of previous pancreatic necrosis, but in some cases the cyst may be partially or fully located in the parenchyma.

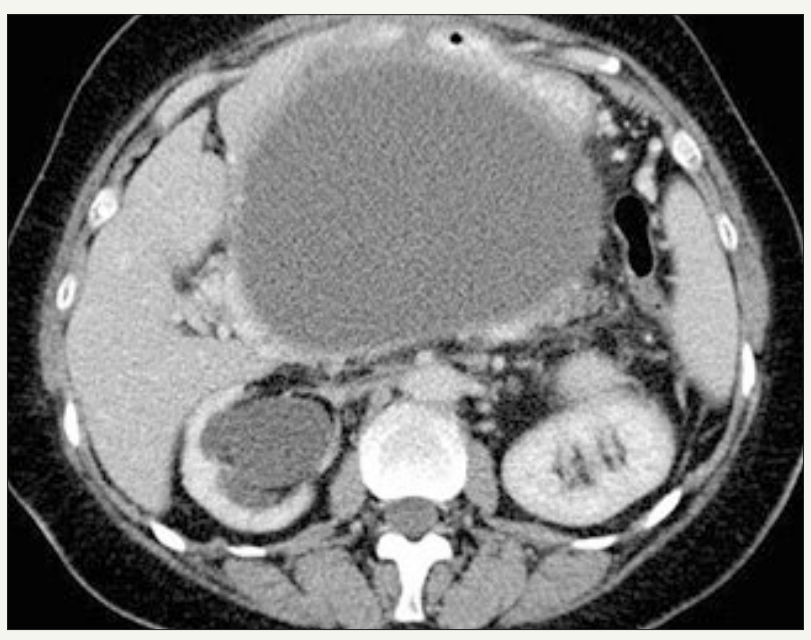

Figure 3A: Typical CT.

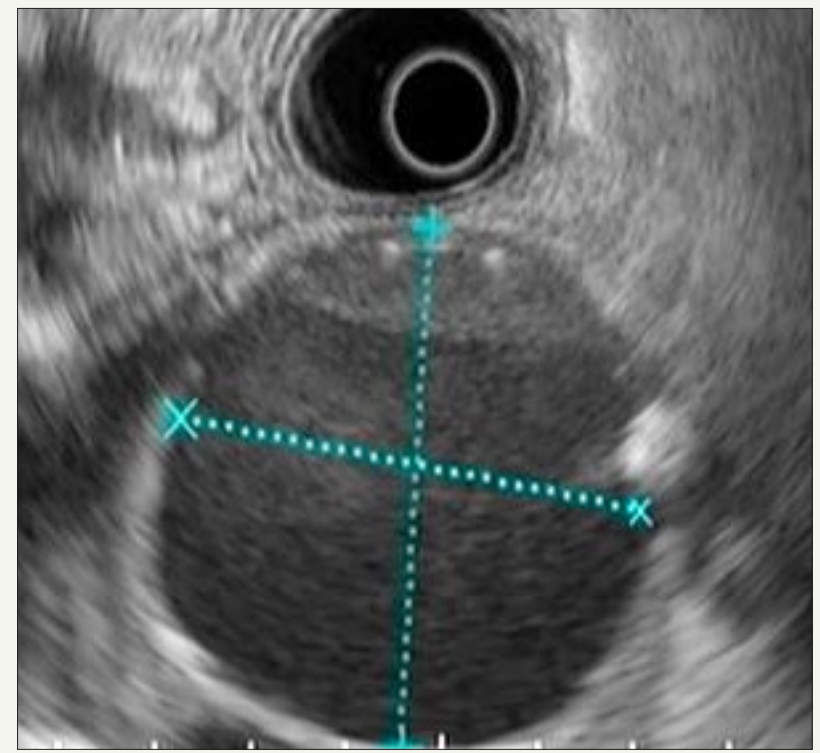

Figure 3B: Typical EUS appearance.

Figure 3: Pancreatic pseudocyst.

\section{Intraductal papillary mucinous neoplasm (IPMN)}

This type of neoplasm was first described by Ohashi $\mathrm{K}$ et al in 1982, using the example of the pathology of the major duodenal papilla [26]. IPMN defined as cystic neoplasm formed from a mucinsecreting, papillary cells present on the surface of the pancreatic ducts $[10,27]$. If neoplasm located in the main pancreatic duct, then it is called the IPMN of the main duct, or MD-IPMN. Neoplasm, which is located in the branch duct, is called the IPMN of the branch duct, or BD-IPMN. In some cases, neoplasm has characteristics of both types and IPMN called mixed type (Figure 4A,4B \& 4C). The management of patient with mixed type IPMN equivalent to MDIPMN [28]. 


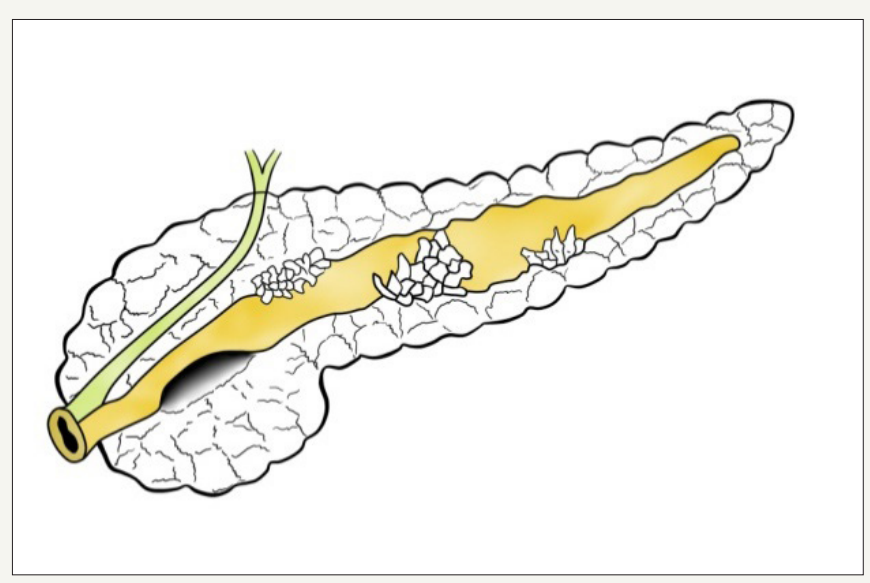

Figure 4A: MD-IPMN

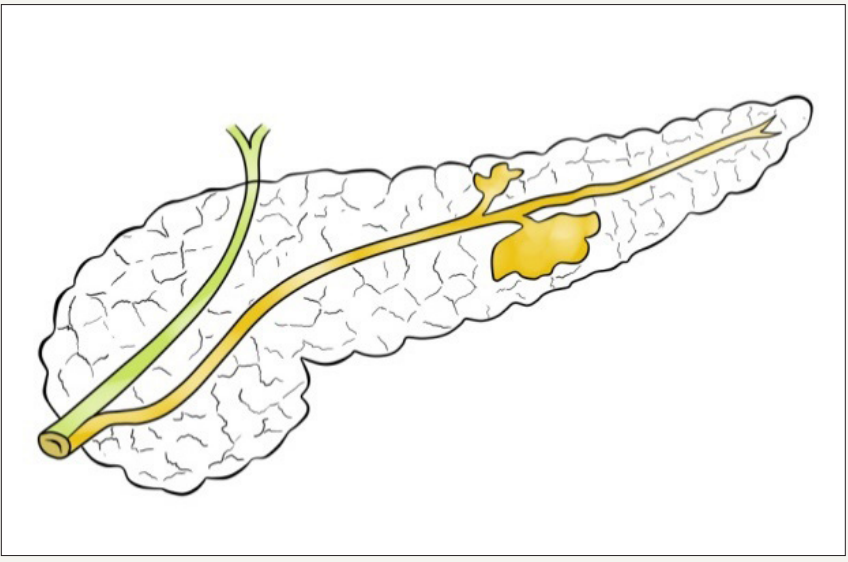

Figure 4B: BD-IPMN

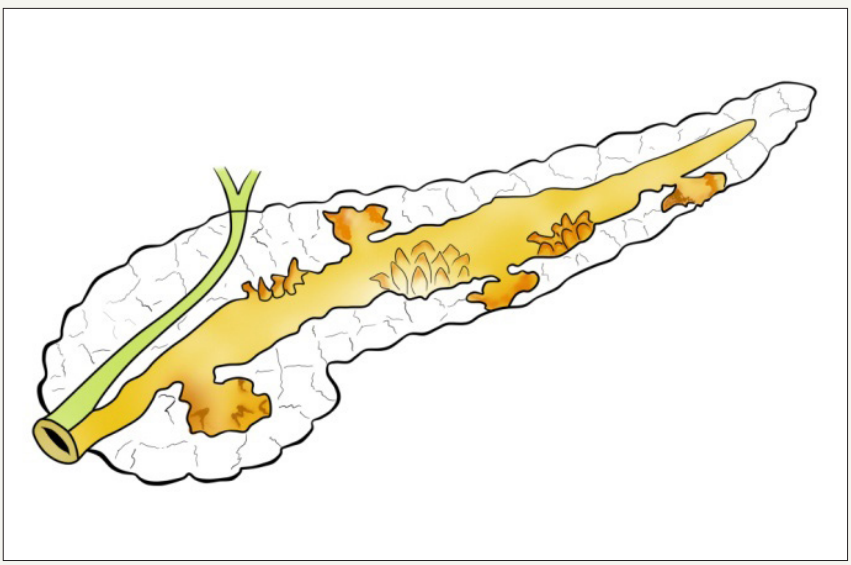

Figure 4C: Mix type IPMN.

Figure 4: Schema of different types of IPMN.

Mechanism of development of cysts at IPMN consists in that the duct is accumulated mucinous content that is poorly drained, which leads to duct dilatation, as well as its proximal segment [29]. Methods of medical visualization defined MD-IPMN as a main pancreatic duct dilatation, which can be either local or diffuse (Figure 5A-5F). In the international consensus on the management of pancreatic mucinous cysts [2], MD-IPMN criteria are given. Thus, the threshold value of the diameter of the main pancreatic duct is $5 \mathrm{~mm}$. It is important to exclude other causes of obstruction. Since mucous fills the main pancreatic duct, it is another sign that clearly indicates the presence of the patient's MD-IPMN - symptom of "fish mouth". During the endoscopic examination we can see the expansion of the mouth of a large duodenal papilla, due to mucus, prolapsing into the duodenum [12]. BD-IPMN - pancreatic cyst diameter greater than $5 \mathrm{~mm}$, which communicates with the side brunch pancreatic duct (Figure 6A \& 6B). If the patient has a history of chronic pancreatitis, differential diagnosis with pseudocyst should be carried out [2]. 

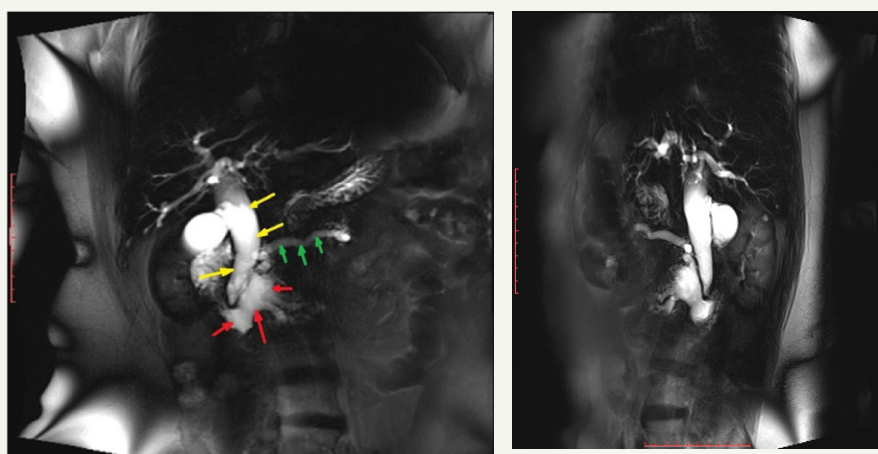

Figure 5A \& 5B : MRCP view of cystic enlarged pancreatic duct in the head of the pancreas (red arrows) and moderate enlargement in the body (green arrows) and enlarged common bile duct due to compression in the terminal part (yellow arrows).

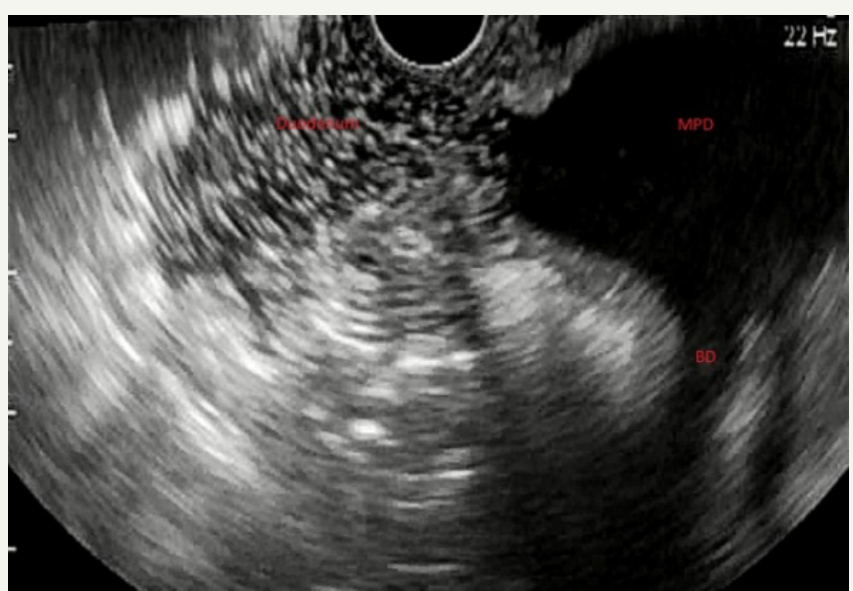

Figure 5C: EUS view of enlarged main pancreatic duct with enlarged branch ducts in the head of the pancreas.

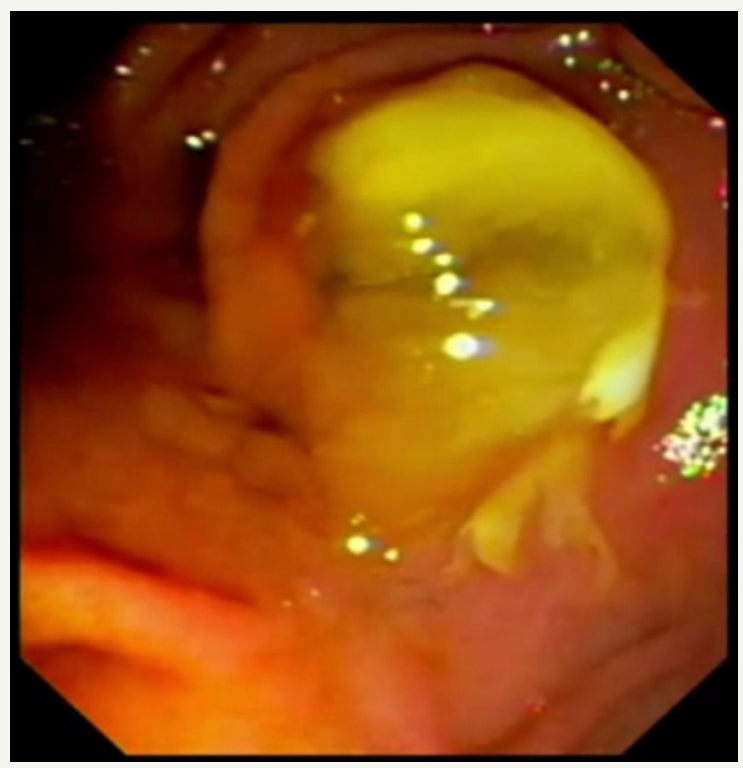

Figure 5E: Mucous prolapses through the mouth of large duodenal papilla.

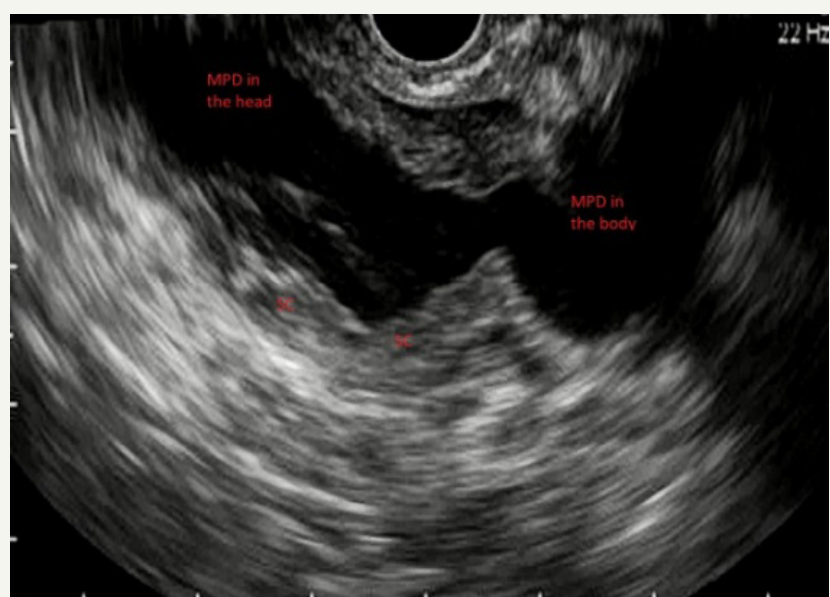

Figure 5D: EUS view of enlarged main pancreatic duct in the head and the body of the pancreas with solid component.

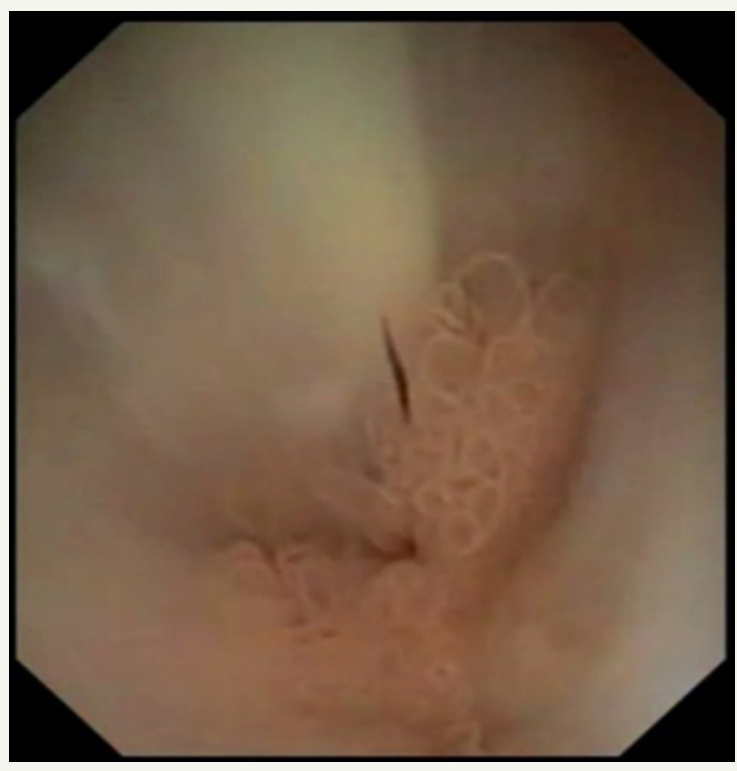

Figure 5F: Pancreaticoscopia; pseudopappilar epithelium with strands of mucus in the main pancreatic duct.

Figure 5: Case of MD-IPMN with signs of malignancy.

MPD: Main Pancreatic Duct; BD: Branch Duct; SC: Solid Component 


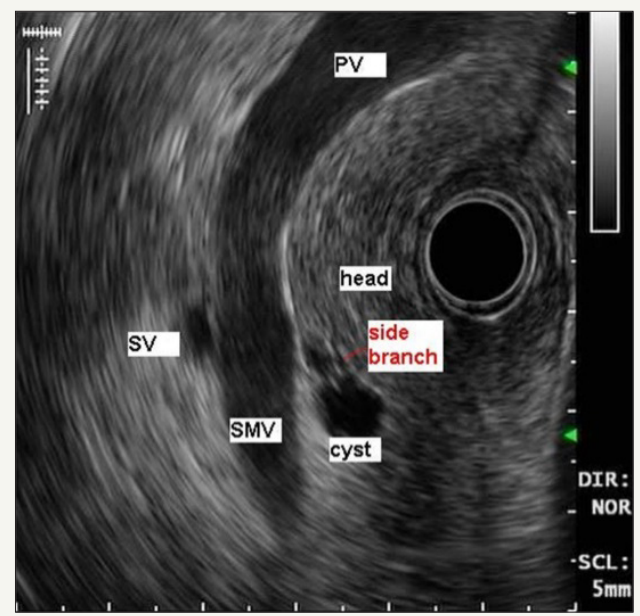

Figure 6A

Figure 6B



Figure 6A \& 6B: EUS shows communication of the cyst with branch pancreatic duct.

PV: Portal Vein; SV: Spleenic Vein; SMV: Superior Mesenteric Vein

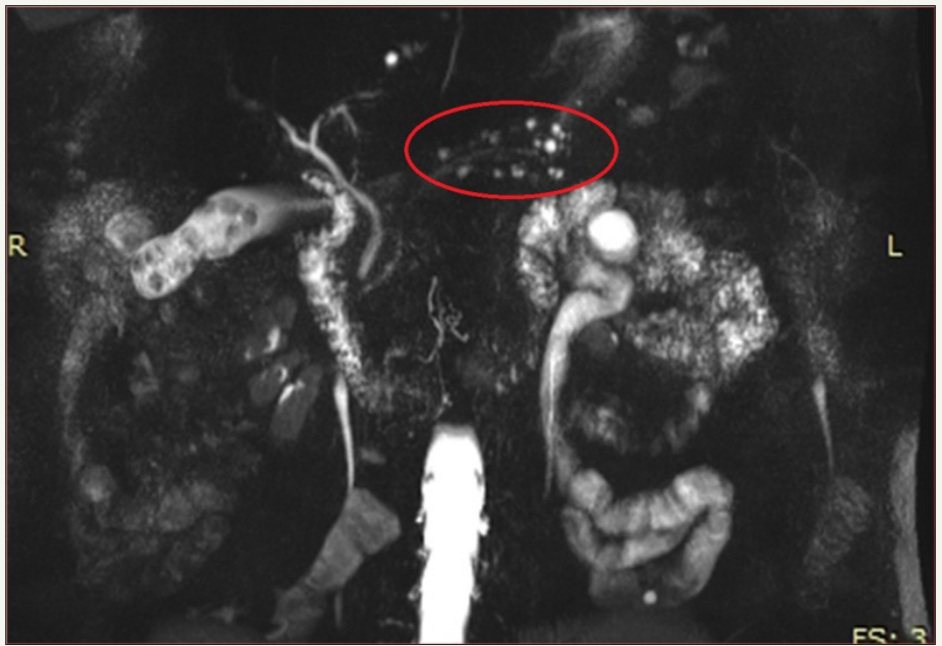

Figure 7: MRCP in patient with multiple BD-IPMN (area in the red oval).

An important feature of BD-IPMN is the possibility of their multiple developing, in any part of the pancreas (Figure 7). Thus, BD-IPMN may be multiple in $20 \%-30 \%$ of cases. They can involve pancreas diffusely in $5 \%-10 \%[30,31]$. This factor influences the choice of surgical tactics and forces to abandon the operation in favor of observation, since initially it is not known which parts of the pancreas are involved in the process, and in which of the cysts the process of malignancy will begin. 


\section{Mucinous cystic neoplasia (MCN)}

MCN is defined as mucin-producing and septated cyst-forming epithelial neoplasia of the pancreas with a distinctive ovarian-type stroma, without communication with pancreatic duct [10,32]. MCN occurs predominantly in women in the fifth decade of life, during premenopausal [33]. However, there are a fairly large number of reports in the literature that show possibility of these neoplasms in men [34-36]. The ratio of women / men is 20/1. The mechanism of cyst formation in MCN is like IPMN, with the difference that mucous does not fill the pancreatic ducts. Therefore, the proximal part of the proximal branch is not visualized. One of the hypotheses for the develop of MCN is the possible incorporation of an ectopic ovarian stroma into the pancreas during embryogenesis. This ectopic tissue releases hormones (estrogen, progesterone) and growth factors, which first promotes the growth of a specific epithelium, and then triggers a cascade of changes leading to malignancy [12,37].
The tumor is represented by a single cyst, with a thick fibrous outer capsule and thin internal septs [38] (Figure 8A \& 8B). The MCN wall is lined from the inside with a single-layer prismatic epithelium containing mucin granules. The irregularity, nodules, cystic inclusions can be visualized on the inner surface of the capsule and septs $[39,40]$. It is important to remember that the presence of such nodules, especially those that accumulate contrast, can be a sign of malignancy. The contents of the cyst are mucinous, viscous, most often transparent, but may have hemorrhagic staining. The mucin staining is positive. The principal visual difference from IPMN is the absent of communication with the pancreatic ducts [12]. However, in some cases, the tumor can compress the pancreatic duct, causing its dilatation in the distal part [41]. A cyst is found more often in the body or tail of the pancreas [42,43]. According to current guidelines, all MCNs should be subjected to surgical resection if the patient who fit for surgery, especially tumors more than $4 \mathrm{~cm}$ and with sings of worrisome or high-risk criteria $[2,44]$.

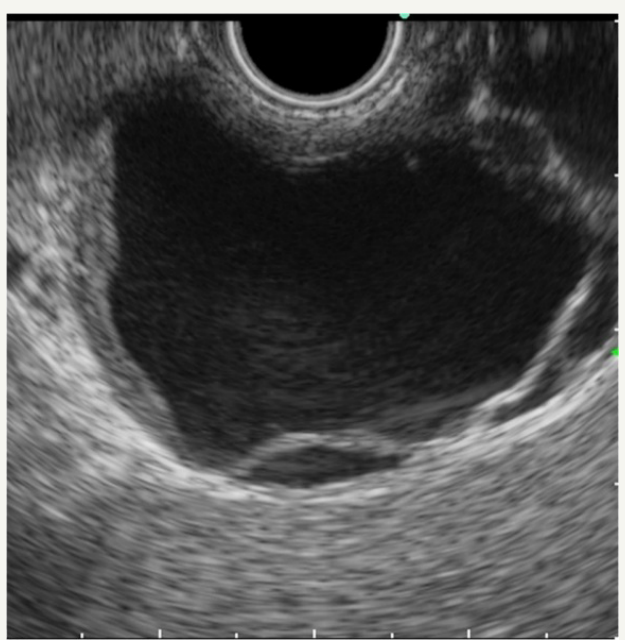

Figure 8A : EUS picture of MCN. EUS-FNA was performed: Amylase: 66MU/1, CEA: 391.8ng/ml, CA 19-9: 2000.00U/ml.

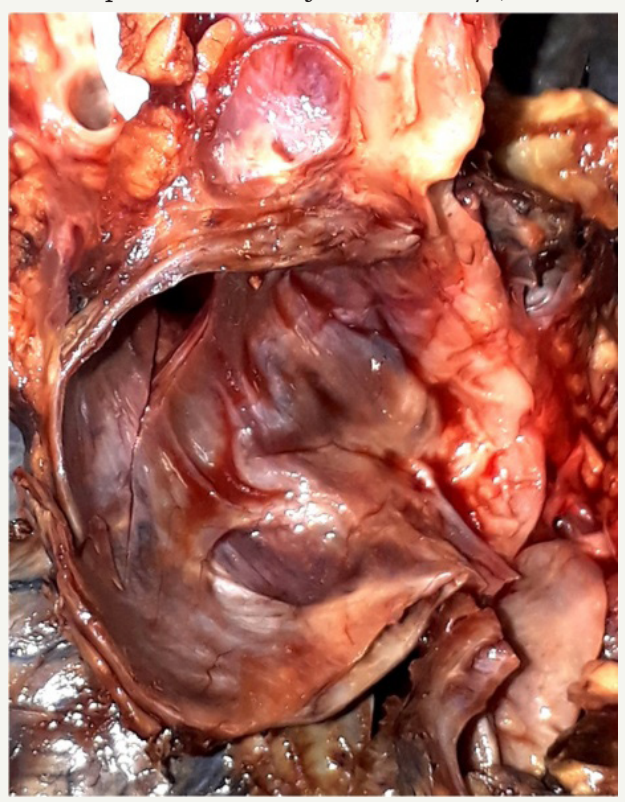

Figure 8B : Section view of postoperative MCN.

Figure 8: Clinical case of MCN in 47 years old woman. 


\section{Serous cystic neoplasia (SCN)}

SCN is a cystic neoplasm filled with serous fluid, originating from centroacinar cells and consisting of cubic glycogen-rich cells [10]. SCN is more common in women, most often in the sixth - seventh decade of life (50-60 years) [12]. The median age is 68 years [45]. Due to its benign nature, such tumors can grow to large sizes, without any symptoms [46]. Usually SCN is a single cyst, of a rounded shape, consisting of many small cysts, ranging in size from millimeters to several centimeters. The presence of microcystic component is called the sign of "honeycomb", which is characteristically of this type of neoplasm [47] (Figure 9A-9C). Often in the center of the tumor can be located fibrous scar $[12,25,33]$. The inner surface of the cyst is lined with a single layer of cubic epithelium. The outer wall and the inner septs of the tumor of a good blood supply. SCN does not communicate with the pancreatic duct. The cyst is filled with a clear serous fluid.

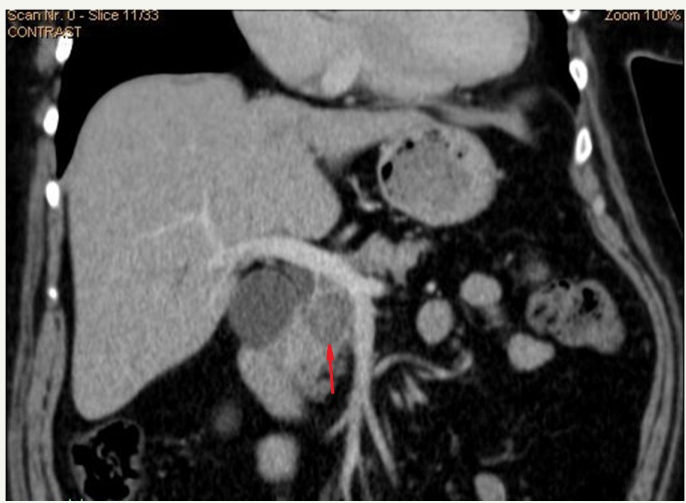

Figure 9A : Clinical case of SCN in 42 years old woman.

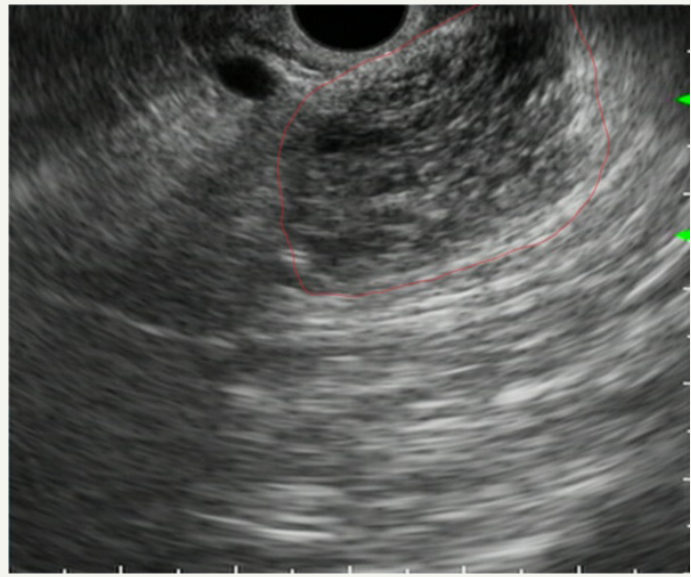

Figure 9B : EUS view of the neoplasm (in the red oval). On EUS imaging we can very well see "honeycomb" sing.

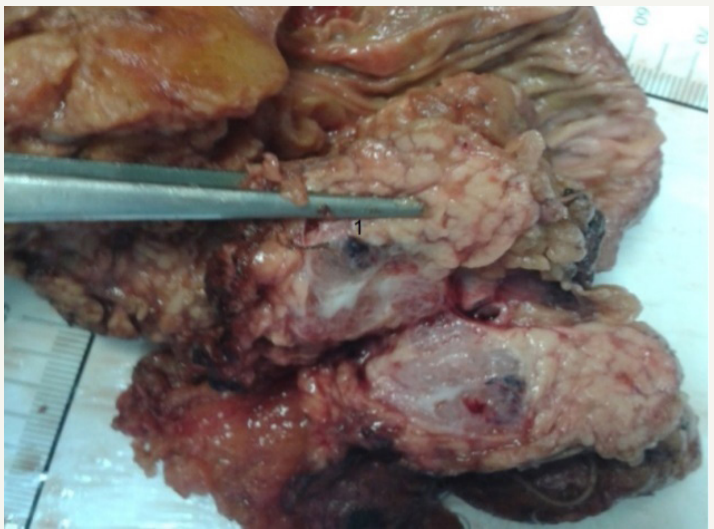

Figure 9C :Postsurgery section view of the tumor.

Figure 9: Clinical case of SCN in 42 years old woman.

According to the WHO classification, SCN are divided into macrocystic and oligocystic type [48]. Japanese authors were proposed a different, more extended classification (Figure 10). In this case, the tumors are divided into three types, depending on the prevalence of microcystic or macrocystic components: 


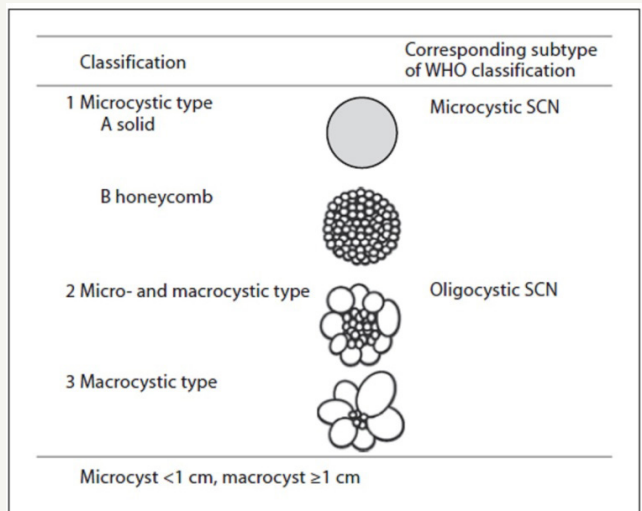

Figure 10: Macroscopic classification of SCN from Fukasawa M et al. [53].

(1) microcystic type,

(2) micro-macrocystic type and

(3) macrocystic.

Microcystic type is divided into solid type and the "honeycomb" type [47].

SCN has a slow growth rate. So, Tseng JF et al. [49] reported that the growth rate of neoplasm was $0.6 \mathrm{~cm}$ per year. Although, tumors larger than $4 \mathrm{~cm}$ has significantly higher growth rate $(1.98 \mathrm{~cm}$ per year). Median time of observation was 2years.

\section{Solid pseudopapillary neoplasia (SPN)}
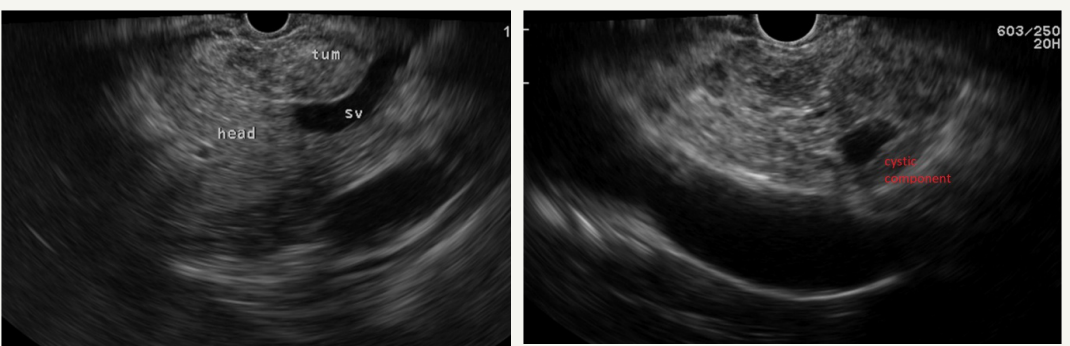

Figure 11A \& 11B: EUS picture of the tumor with area of cystic degeneration.

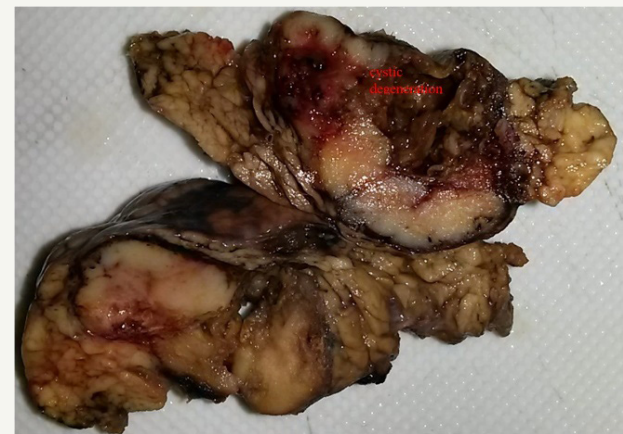

Figure 11C: Sectional view of SPN with solid component and cystic degeneration.

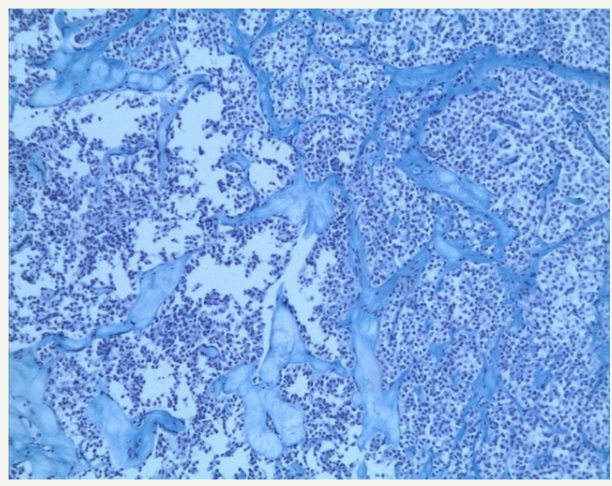

Figure 11D: Histological examination of SPN

Figure 11:Clinical case of SPN in 29 years old woman without any symptoms of pancreatic disease. 
SPN is a high differentiated malignant neoplasm consisting of monomorphic epithelial cells that form solid and pseudopapillary structures [10]. Morphologically, SPN combines a pseudopapillary solid component and a cystic component that resulting from hemorrhagic necrosis. This type of tumor is often has a tendency to hemorrhagic cystic degeneration [50]. Macroscopically, this is a well-defined, single tumor, of various sizes. Since SPN is asymptomatic, large-sized tumors $(8-10 \mathrm{~cm})$ are often detected [12]. The most frequent localization is the tail of the pancreas, however, a number of authors report that the tumors may appear with equal frequency in different parts of the organ [51-54]. In the section, SPNs represent a combination of solid lobular areas, with areas of hemorrhages, necrosis, and cystic degeneration (Figure 11A-11D). The cyst is content not viscous fluid, with hemorrhagic staining, without mucous and poor in glycogen. SPN is detected mainly in young women (84\% - 89\%) in the third decade of life (20-30years). A number of authors report a later median age (32-38years), which is most likely due to a long asymptomatic carriage $[55,56]$.

\section{Rare pancreatic cysts:}

In the pancreas there are other, rare types of cystic tumors that can also be neoplastic or non-neoplastic [57]. Nonneoplastic pancreatic cysts include epidermoid [58] and dermoid cysts [59], duplication, retention, congenital epithelial and lymphoepithelial cysts [60]. The preoperative diagnosis of these types of cysts is extremely difficult [61]. Neoplastic conditions such as lymphangioma [62], hemangioma [63], cystic hamartoma, and acinar cell cystadenoma can manifest as cysts. Some solid tumors can undergo cystic transformation (adenocarcinoma, pancreatoblastoma, sarcoma) [64]. In addition, a number of neoplasms may be of a mixed morphological type. One such example is serous neuroendocrine neoplasia $[48,65]$. The pathology of the splenic vessels may also visualize like a cyst of the pancreas. In our practice, there was a giant aneurysm of the splenic artery, which at the pre-hospital stage was regarded as a pseudocyst of the pancreas (Figure 12A-12C). A similar clinical situation was described by Korean authors [66].

Figure 12A : EUS picture of aneurysm.


Figure 12B: Communication with splenic artery.

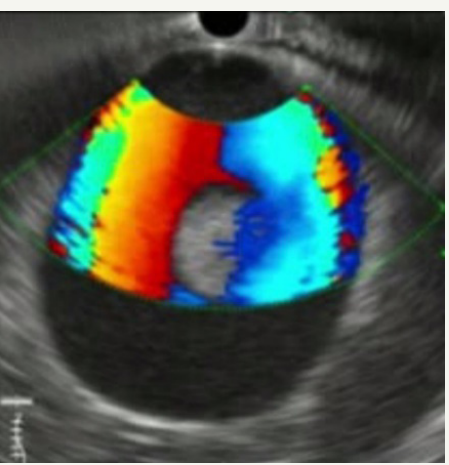

Figure 12C: Dopler color view.

Figure 12: Clinical case of aneurysm of splenic artery that was regarded as a pseudocyst on CT without contrast. Contrast wasn't use because patient had chronic renal failure. 
Extrapancreatic cysts, such as tumors and duplication cysts of the stomach [67], tumors of the left adrenal gland [68], tumors of the spleen $[69,70]$ can imitate pancreatic cysts. In rare cases, echinococcal cysts of the pancreas are found [71]

Cystic neuroendocrine neoplasm must be included in the diagnostic algorithm. The following mechanisms of its development are suggested:

(1) the result of hemorrhagic necrosis,

(2) impaired blood supply to the parenchyma, due to the capsule of the tumor,

(3) intraductal growth $[72,73]$. Despite the mechanism of forming, there is no clinical difference between the solid and cystic forms of neuroendocrine neoplasm [74]. Comparative studies have not find a significant difference in the five-year survival rate between solid and cystic neoplasms $[75,76]$. Neuroendocrine cystic neoplasm is a rounded tumor, with the presence of solid and cystic components in various ratios. The capsule and the solid component of the tumor has a good vascularisation. Calcifications are rarely visualized in the structure $[77,78]$.

\section{Potential for Malignancy of Pancreatic Cystic Neo- plasms}

Oncogenesis in the pancreas goes through several stages, which consist of the formation of a precancerous change, a further change in the degree of dysplasia and the formation of foci of malignancy [79]. One of the strategies for early detection of pancreatic cancer is to detect changes that precede its development. MCN, IPMN, SPT, cystic neuroendocrine neoplasia, are precursors of pancreatic cancer [80]

Mucinous cysts have the highest malignant potential from other cystic neoplasms. The risk of developing invasive carcinoma in IPMN is $27.6 \%-68 \%$ [81,82]. The WHO classification, IPMN is divided into three morphological subgroups, according to the grade of dysplasia: I - IPMN with mild or moderate dysplasia; II - IPMN with a high grade of dysplasia (essentially cancer in situ); III IPMN associated with invasive carcinoma [83,84]. In addition, four histological subtypes of IPMN are distinguished: gastric, intestinal, pancreatobiliary, and oncocytic. So, BD-IPMN is more characteristic of the gastric type, while MD-IPMN is more intestinal [85].

Patients with gastric type IPMN are known to have a better prognosis, while pancreatobiliary and intestinal types have a poor prognosis [29]. The probability of development of invasive carcinoma is $9.4 \%$ for gastric type IPMN, $41.6 \%$ for intestinal, $63.2 \%$ for pancreatobiliary and $45.8 \%$ for oncocyte. Depending on the histological subtype, various types of carcinoma develop, respectively, the proportion of postoperative relapse and five-year survival differ [80]. As in the overwhelming majority of cases, BDIPMN belong to the gastric histological subtype, the prognosis of these neoplasm is favorable, with a five-year survival rate for invasive carcinoma $70-93.7 \%[86,87]$.

For MCN, the likelihood of developing invasive carcinoma is about $17 \%[80,88,89]$. Like IPMN, MCN is histologically divided

into three types, depending on the severity of dysplastic changes: I - MCN with mild or moderate dysplasia; II - MCN with a high grade of dysplasia (essentially cancer in situ); III - MCN associated with invasive carcinoma [83]

For all MCN a five-year survival rate of $75 \%-93 \%$. At the same time, in the MCN group with non-invasive carcinoma surgical treatment resulted in close to $100 \%$ and for invasive carcinoma fiveyear survival of $26 \%$ to $57 \%[43,90]$. In the international consensus [2] and in the WHO classification [91], it is recommended not to use the term "carcinoma in situ", but to equate it with a high grade of dysplasia. The definition of malignant mucinous neoplasm is applicable only to invasive carcinoma.

The visual signs of the mucinous neoplasms are known. Such signs are divided into two groups:

1. Signs of high risk (High-risk stigmata) and

Table 1: High-risk stigmata and Worrisome features regardless International consensus-2012 [2].

\begin{tabular}{|c|}
\hline High-Risk Stigmata \\
\hline Mechanical jaundice in patients with cystic pancreatic head lesions \\
\hline A solid component with contrast enhancement within the cyst \\
\hline Diameter of main pancreatic duct $>10 \mathrm{~mm}$ \\
\hline Cytology suspicious ore positive for malignancy \\
\hline Worrisome Features \\
\hline Cyst $>3$ cm \\
\hline Thickened/contrast-enhanced cyst walls \\
\hline Lymphadenopathy \\
\hline Pancreatitis \\
\hline
\end{tabular}

Table 2: Factors highly predictive of malignancy and Increased risk for high-grade dysplasia or cancer regardless European evidence-based guidelines on pancreatic cystic neoplasms [68].

\begin{tabular}{c}
\hline Factors Highly Predictive of Malignancy \\
Jaundice \\
Enhancing mural nodule $(\geq 5 \mathrm{~mm})$ \\
solid component, \\
positive cytology, \\
MPD measuring $\geq 10 \mathrm{~mm}$ \\
\hline Increased Risk for High-grade Dysplasia or Cancer \\
MPD dilatation between 5 and $9.9 \mathrm{~mm}$ \\
Cystic growthrate $\geq 5 \mathrm{~mm} /$ year \\
Increased level of serum CA $19.9(>37 \mathrm{U} / \mathrm{mL})$ \\
Symptoms, enhancing mural nodules $(<5 \mathrm{~mm})$ \\
Cyst diameter $\geq 40 \mathrm{~mm}$
\end{tabular}


2. Alarming signs (worrisome features) (Table 1) [2]. The criteria for international consensus are very close to the criteria of the European group [44] (Table 2). Thus, the dilatation of the main pancreatic duct more than $10 \mathrm{~mm}$ is a positive predictive factor for the malignancy of IPMN in $56-89 \%$ (Figure 13A \&13B).

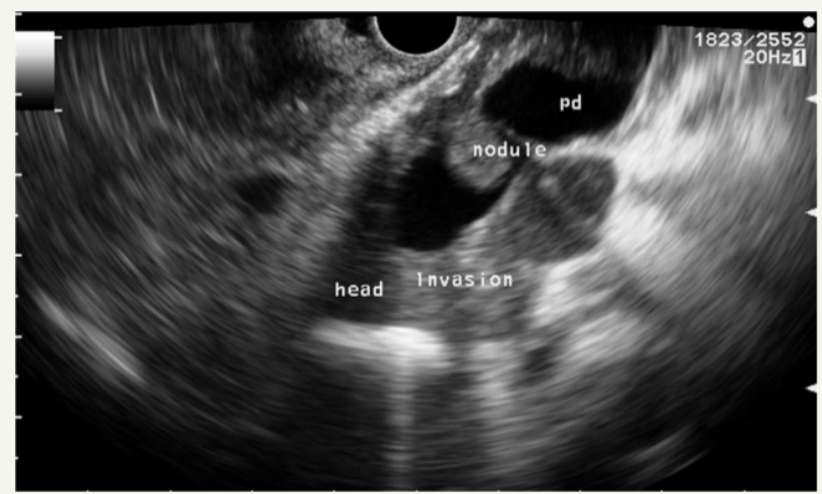

Figure 13A : EUS picture of enlarged pancreatic duct (PD) with solid components and intramural nodule in the neck of the pancreas.

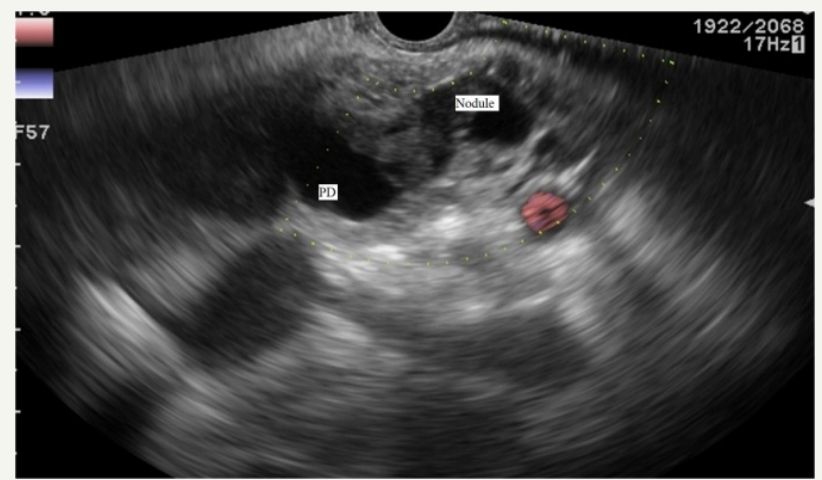

Figure 13B: EUS picture of pancreatic duct in the body.

Figure 13: Case of MD-IPMN with sings of invasive carcinoma.

The risk of malignancy in SCN is extremely low and different authors estimated it at $0.2-3 \%[25,33,92]$. Tseng et al. [48] studied the growth rate and biology of the tumor. The team came to the conclusion that the biological features of the cyst may vary depending on the size of the tumor. The transformation of large tumors becomes more aggressive. In 1989, George et al. [93] described a malignant variant of SCN, calling it a serous cystadenocarcinoma. Since then, in the literature periodically there are reports of a malignant variant of SCN [92,94-102]. Serous cystadenocarcinoma manifests metastases in adjacent organs and tissues. In most cases, the liver and locoregional lymph nodes are affected. All malignant tumors were symptomatic and in $89 \%$ of cases their size was more than $10 \mathrm{~cm}$. At the same time, vascular and renal invasion, as well as local invasion into the stomach or duodenum are not a sign of SCN malignancy [103]. In the study of Fukasawa M et al. [47], long-term follow up of SCN did not lead to the malignancy of tumors in any of the cases. Surgical resection was performed due to the growth of neoplasm and the inability to evaluate in detail all parts of the tumor. In addition, the European Pancreatic Cystic Study Group reports that, specific mortality due to an SCN is nearly zero. The researchers note that the known cases of the detected of serous cystadenocarcinomas [92,104,105] do not fulfill the WHO criteria for a SCN. The authors propose to consider the potential for the malignancy of SCN approaching to zero [44].
The surgical treatment of asymptomatic, small-sized serous cysts carries greater operational risks than the risks of follow up of the neoplasm [45]. Moreover, the observation of SCN may be symptomatic, if a year after the discovery of the tumor, an increase in the size was not detected [44]. Solid pseudopapillary neoplasm (SPN) are classified as tumor with a low potential for malignancy $[106,107]$. They can metastasize without morphological criteria for malignancy, such as vascular invasion or infiltration of surrounding tissues [12]. The frequency of metastasis is $10-15 \%$ and depends on the tumors size $[56,61,106,108,109]$. Surgical treatment of these tumors is recommended, regardless of the presence of symptoms or size [44]. The prognosis after surgical treatment is favorable, even despite the presence of local metastases. The five-year survival rate is about $95 \%$ [28].

\section{Approaches to the Differential Diagnosis of Cystic Neoplasias}

Cystic neoplasms of small size are random findings in asymptomatic patients in most cases, so their targeted search is rarely carried out. But these structures are the most difficult for differential diagnosis. The diagnostic algorithm includes the interview of the patient of his anamnesis and complaints, laboratory tests, medical imaging methods (US, CT, MRI, EUS), morphological verification and analysis of the cyst contents. 
The key questions that need to be answered in the research process are as follows:

(1) whether this cyst is a neoplasm;

(2) if so, what type of neoplasm: mucinous or non-mucinous;

(3) whether there are signs of cystic neoplasm malignancy;

(4) if not, what is the potential for the malignancy of this neoplasm [107].

The first step of the diagnostic algorithm is to exclude or confirm the presence of pseudocysts. The pseudocyst is not difficult to diagnose in most cases. In addition, this is the most common cause of pancreatic cysts as was mentioned above [24]. SPN is found predominantly in young women, and the cystic form of neuroendocrine tumor is an extremely rare. So, if a pseudocyst is excluded, then the main diagnostic search is conducted between MCN, IPMN and SCN. Other types of pancreatic cysts are encountered in isolated cases less frequently [57].

At the initial assessment of the patient, it is necessary to pay attention to the following details: the patient's age, gender, the presence of a history or symptoms of chronic pancreatitis, heredity. The choice of medical imaging methods is one of the controversial issues, which, however, is covered in detail in the clinical guidelines. In order to save the patient from unreasonable risks (radiation during CT, the risks of anesthesia and endoscopy with EUS), as well as reduce financial costs, it is necessary to understand what important additional information each study carries [2,44]. Standard transabdominal ultrasound may be proposed as a screening method. However, given the resolution of the method, the complexity of visualization of the pancreas, this method is not suitable for a detailed assessment of the identified changes.

CT scan is one of the most common methods for treating pancreatic cysts. The main bonuses of CT are the ability to assess the overall picture of the pancreato-biliary zone and abdominal organs, identify signs of chronic pancreatitis, determine the contrast enhancement of the neoplasm and identify additional areas that accumulate contrast. $[110,111]$. However, this method is not ideal for a detailed assessment of the structure of the cyst, the presence of internal structures, the determination of the microcystic component, and its connection with the pancreas duct [61]. In addition, CT is the source of patient radiation, and therefore, unnecessary research should be avoided [2,44]. The MRI with MRCP mode, is an ideal method for detecting pancreatic cyst and determining its connection with the pancreatic duct [112]. The method also allows us to estimate the overall picture of the abdominal cavity, to identify the anatomical features of the pancreatobiliary system $[113,114]$.

EUS is able to identify the smallest details of the structure of cystic neoplasm, including internal structures, identify areas of microcystic transformation, internal nodes and a solid component, signs of invasive growth $[2,44,114]$. In small cysts, EUS is effective in determining the association of a cyst with the pancreatic duct. The contrast enhancement EUS (CH-EUS) allows to determine the features of the blood supply to neoplasm. In differential diagnosis of the internal nodes of cystic neoplasm, CH-EUS is superior to EUS without contrast enhancement $[115,116]$. The fine needle aspiration (EUS-FNA) is performed to evaluate the contents of the cyst. The sensitivity of the cytology is low, especially in the absence of a solid component. In this regard, a comprehensive assessment of punctate should be carried out. Ideally, the following diagnostic methods should be performed: cytology, level of amylase, lipase, staining for mucin, detection of tumor markers (CA 19-9, CEA), GNAS and KRAS mutations [32,44,117]. During EUS-FNA, confocal laser endomicroscopy can also be performed.

Large cysts are difficult to evaluate using EUS, since it is impossible to estimate the edges farther from the scanning zone. One of the limitations of EUS is its operator dependence [114,118]. In addition, it is necessary to take into account the increased risks of complications during FNA, which include infection of the cyst, bleeding, and the spread of tracer metastases [119-122].

Jenssen C \& Kahl S [123] offer estimates of cystic neoplasm with the FLAGS (frequency, localization, age, gender, symptoms) system (Table 3). For example, if a cyst is found in the head of the pancreas in a 70-year-old man, the probability of MCN approaches zero [124]. Confocal laser endomicroscopy (CLE) is a newly invented endoscopic method that allows imaging of the mucosal layer during endoscopy at a subcellular level of resolution. Therefore, evaluation of changes in vascular architecture, connective tissue, and cellular components in the mucosa, as well as collecting real time in vivo histological images or optical biopsies of the gastrointestinal mucosa during the endoscopy will be facilitated by this modality. CLE techniques using needle-based confocal laser endomicroscopy (nCLE) that uses a miniprobe passing through a 19G needle for pancreatic cystic tumors, pancreatic masses, and lymph nodes [125].

The combination of the papillary projections feature, cytology and CEA level has been shown to have a sensitivity of $100 \%$ for the characterization of IPMN. Dense network of small vessels on a dark background is characteristic of neuroendocrine tumors in nCLE [126]. There is controversial information in recent literature about use of PET scan or PET/CT scan in management of pancreatic cystic lesions. Some preliminary investigation suggests that $18 \mathrm{~F}$-fluorodeoxyglucose positron emission tomography may be helpful in detection of malignant forms of IPMNs. But in the present time CLE and PET/CT doesn't include in the international or national guidelines [127].

\section{Conclusion}

Differential diagnosis of cystic neoplasms is a complex clinical task requiring an integrated approach. Late or incorrect diagnosis of cystic neoplasm can lead to the choice of the wrong management, loss of time and the development of invasive pancreatic cancer and/ or the performance of unreasonable surgical treatment.

Briefly, the keys for differential diagnosis are the following features of neoplasms [2,8,10,12,24,39]: Clinical symptoms and visual signs of acute or chronic pancreatitis are characteristic of 
pseudocysts. The pseudocyst is delimited by a well-marked smooth fibrous capsule, does not have an epithelial lining, contains a flowable fluid with a large amount of amylase, stains for mucin are negative, the level of tumor markers is low [119]. The sensitivity of the cytological method is low. BD-IPMN - cystic neoplasm formed in the branch duct of the pancreas. Visually, it can resemble a bunch of grapes. The contents of the cyst - a viscous fluid, with a positive stain on mucin, a high level of amylase, tumor markers can be positive. The task of medical visualization is to check the connection with the pancreatic duct and the absence of signs or the presence of malignancy. BD-IPMN can often be multiple. The sensitivity of the cytological method is low.

MD-IPMN is determined by the dilation of the pancreatic duct ( $\geq 5 \mathrm{~mm}$ ), without any clinical symptoms of pancreatitis, with no other causes of obstruction. An additional sign is the "symptom of a fish mouth", when endoscopically the dilatation of the mouth of the major duodenal papilla is determined by the prolapse of mucus into the lumen of the duodenum. Cytological sensitivity is low. MCN is a single cyst, with a distinct external capsule, internal septas, not connected with the pancreatic duct. In the classic case, the visual picture is similar to an orange slice. The disease occurs predominantly in women during the premenopausal period. EUSFNA shows the viscous, positive for mucin, low amylase, high levels of CEA, CA-19-9 fluids. Cytological sensitivity is low

SCN is a thin-walled cystic tumor with a microcystic component not connected with the pancreatic duct. EUS-FNA shows a bright, clear fluid with a low level of amylase, tumor markers and negative for mucin. The sensitivity of cytological study is low. SPN is a tumor with solid and cystic components, which is found mainly in young women (20-30 years old). EUS-FNA shows hemorrhagic fluids, with a low level of amylase, and negative staining for mucin. The diagnosis can be made as a result of morphological study of aspirate.

\section{References}

1. Megibow AJ, Baker ME, Gore RM, Taylor A (2011) The incidental pancreatic cyst. Radiol Clin North Am 49(2): 349-359.

2. Tanaka M, Fernandez del CC, Adsay V, Chari S, Falconi M, et al. (2012) International consensus guidelines for the management of IPMN and MCN of the pancreas. Pancreatology 12(3): 183-197.

3. Chernyak V, Flusberg M, Haramati LB, Rozenblit AM, Bellin E (2015) Incidental pancreatic cystic lesions: Is there a relationship with the development of pancreatic adenocarcinoma and all-cause mortality? Radiology 274(1): 161-169.

4. Birkmeyer JD, Finlayson SR, Tosteson AN, Sharp SM, Warshaw AL et al. (1999) Effect of hospital volume on in-hospital mortality with pancreaticoduodenectomy. Surgery 125(3): 250-256.

5. Gomez D, Rahman SH, Wong LF, Verbeke CS, Menon KV (2008) Predictors of malignant potential of cystic lesions of the pancreas. Eur J Surg Oncol 34(8): 876-882.

6. Birkmeyer JD, Warshaw AL, Finlayson SR, Grove MR, Tosteson AN (1999) Relationship between hospital volume and late survival after pancreaticoduodenectomy. Surgery 126(2): 178-183.

7. Javia S, Munigala S, Guha S, Agarwal B (2017) EUS Morphology Is Reliable in Selecting Patients with Mucinous Pancreatic Cyst(s) Most Likely to Benefit from Surgical Resection. Gastroenterology Research and Practice 2017: 9863952.
8. Lee LS (2014) Diagnostic approach to pancreatic cysts. Curr Opin Gastroenterol 30(5): 511-517.

9. Goh BK, Tan YM, Tan PH, Ooi LL (2005) Mucinous nonneoplastic cyst of the pancreas: A truly novel pathological entity? World J Gastroenterol 11(13): 2045-2047.

10. Yoon WJ, Brugge WR (2012) Pancreatic cystic neoplasms: Diagnosis and management. Gastroenterol Clin North Am 41(1): 103-118.

11. Spinelli KS, Fromwiller TE, Daniel RA, Kiely JM, Nakeeb A, et al. (2004) Cystic pancreatic neoplasms: observe or operate. Ann Surg 239(5): 651657.

12. Brugge WR (2015) Diagnosis and management of cystic lesions of the pancreas. J Gastrointest Oncol 6(4): 375-388.

13. Habashi S, Draganov PV (2009) Pancreatic pseudocyst. World J Gastroenterol 15(1): 38-47.

14. Ammann RW, Akovbiantz A, Largiader F, Schueler G (1984) Course and outcome of chronic pancreatitis. Longitudinal study of a mixed medicalsurgical series of 245 patients. Gastroenterology 86(5 Pt 1): 820-828.

15. O'Malley VP, Cannon JP, Postier RG (1985) Pancreatic pseudocysts: cause, therapy, and results. Am J Surg 150(6): 680-682.

16. Cannon JW, Callery MP, Vollmer CM (2009) Diagnosis and management of pancreatic pseudocysts: What is the evidence? J Am Coll Surg 209(3): 385-393.

17. Bollen TL, van Santvoort HC, Besselink MG, van Leeuwen MS, Horvath KD, et al. (2008) The Atlanta Classification of acute pancreatitis revisited. Br J Surg 95(1): 6-21.

18. Zhou ZG, Zheng YC, Shu Y, Hu WM, Tian BL, et al. (2003) Laparoscopic management of severe acute pancreatitis. Pancreas 27(3): e46-e50.

19. Maringhini A, Uomo G, Patti R, Rabitti P, Termini A, et al. (1999) Pseudocysts in acute nonalcoholic pancreatitis: incidence and natural history. Dig Dis Sci 44(8): 1669-1673.

20. Soliani P, Franzini C, Ziegler S, Del RP, Dell'Abate P, et al. (2004) Pancreatic pseudocysts following acute pancreatitis: risk factors influencing therapeutic outcomes. JOP 5(5): 338-347.

21. De Waele J, Vogelaers D, Decruyenaere J, De Vos M, Colardyn F (2004) Infectious complications of acute pancreatitis. Acta Clin Belg 59(2): 9096.

22. Aghdassi A, Mayerle J, Kraft M, Sielenkämper AW, Heidecke CD, et al. (2008) Diagnosis and treatment of pancreatic pseudocysts in chronic pancreatitis. Pancreas 36(2): 105-112.

23. Banks PA, Bollen TL, Dervenis C, Gooszen HG, Johnson CD, et al. (2013) Classification of acute pancreatitis-2012: Revision of the Atlanta classification and definitions by international consensus. Gut 62(1): 102-111.

24. Costa PRL, Meneses Rêgo AC, Araujo FI (2016) Pancreatic cystic lesions: classification, diagnosis and treatment. Int Surg J 3(2): 443-451.

25. Bauer F (2017) Pancreatic cystic lesions: Diagnostic, management and indications for operation. Part I. Chirurgia (Bucur) 112(2): 97-109.

26. Ohashi K, Murakami Y, Takekoshi T (1982) Four cases of mucinproducing cancer of the pancreas on specific findings of the papilla of Vater. Prog Dig Endosc 20: 348-351.

27. Farrell JJ, Brugge WR (2002) Intraductal papillary mucinous tumor of the pancreas. Gastrointest Endosc 55(6): 701-714.

28. Bauer F (2018) Pancreatic cystic lesions: Diagnostic, management and indications for operation. Part II. Chirurgia (Bucur) 113(3): 318-334.

29. Morales Oyarvide V, Fong ZV, Fernández Del CC, Warshaw AL (2017) Intraductal papillary mucinous neoplasms of the pancreas: Strategic considerations. Visc Med 33(6): 466-476. 
30. Sahani DV, Lin DJ, Venkatesan AM, Sainani N, Mino Kenudson M, et al. (2009) Multidisciplinary approach to diagnosis and management of intraductal papillary mucinous neoplasms of the pancreas. Clin Gastroenterol Hepatol 7(3): 259-269.

31. Kang MJ, Lee KB, Jang JY, Kwon W, Park JW, et al. (2013) Disease spectrum of intraductal papillary mucinous neoplasm with an associated invasive carcinoma invasive IPMN versus pancreatic ductal adenocarcinomaassociated IPMN. Pancreas 42(8): 1267-1274.

32. Testini M, Gurrado A, Lissidini G, Venezia P, Greco L, et al. (2010) Management of mucinous cystic neoplasms of the pancreas. World J Gastroenterol 16(45): 5682-5692.

33. Graham R, Smyrk T (2015) Pathology of Pancreatic Cystic Neoplasms. In: Sakorafas (Eds.), Pancreatic Cystic Neoplasms: From Imaging to Differential Diagnosis and Management. Springer, Milano, Italy, pp. 11 24.

34. Wouters K, Ectors N, Van Steenbergen W, Aerts R, Driessen A, et al. (1998) A pancreatic mucinous cystadenoma in a man with mesenchyma stroma, expressing oestrogenand progesterone receptors. Virchows Arch 432(2): 187-189.

35. Suzuki M, Fujita N, Onodera H, Kayaba Y, Suzuki S, et al. (2005) Mucinous cystic neoplasm in a young male patient. J Gastroenterol 40(11): 10701074.

36. Casadei R, Pezzilli R, Calculli L, Santini D, Taffurelli G, et al. (2012) Pancreatic mucinous cystic neoplasm in a male patient. JOP 13(6): 687689.

37. Sano M, Driscoll DR, De Jesus Monge WE, Klimstra DS, Lewis BC (2014) Activated want signaling in stroma contributes to development of pancreatic mucinous cystic neoplasms. Gastroenterology 146(1): 257 267.

38. Naveeda S, Qaria H, Bandayb T, Altafc A, Parad M (2014) Mucinous cystic neoplasms of pancreas. Gastroenterology Res 7(2): 44-50

39. Kechagias D, Laspas F (2015) Imaging of pancreatic cystic neoplasms In: Sakorafas G (Eds.), Pancreatic Cystic Neoplasms: From Imaging to Differential Diagnosis and Management. Springer, Milano, Italy, pp. 3752.

40. Khan A, Khosa F, Eisenberg RL (2011) Cystic lesions of the pancreas. Am J Roentgenol 196(6): W668-W677.

41. Sakorafas GH, Smyrniotis V, Reid Lombardo KM, Sarr MG (2011) Primary pancreatic cystic neoplasms revisited: Part II: Mucinous cystic neoplasms. Surg Oncol 20(2): e93-e101.

42. Fernández del Castillo C (2008) Mucinous cystic neoplasms. Gastrointest Surg 12(3): 411-413

43. Crippa S, Salvia R, Warshaw AL, Domínguez I, Bassi C, et al. (2008) Mucinous cystic neoplasm of the pancreas is not an aggressive entity: lessons from 163 resected patients. Ann Surg 247(4): 571-579

44. The European Study Group on Cystic Tumors of the Pancreas (2018) European evidence-based guidelines on pancreatic cystic neoplasms. Gut 67(5): 789-804.

45. Hwang HK, Chung YE, Kim HK, Park JY, Choi HJ, et al. (2011) Serous cystic neoplasm: do we have to wait till it causes trouble? Korean J Hepatobiliary Pancreat Surg 15(2): 134-138.

46. Sakorafas GH, Smyrniotis V, Reid Lombardo KM, Sarr MG (2011) Primary pancreatic cystic neoplasms revisited. Part I: Serous cystic neoplasms. Surg Oncol 20(2): e84-e92.

47. Fukasawa M, Maguchi H, Takahashi K, Katanuma A, Osanai M, et al. (2010) Clinical features and natural history of serous cystic neoplasm of the pancreas. Pancreatology 10(6): 695-701.

48. Capella C, Solcia E, Klöppel G, Hruban RH (2000) Serous cystic neoplasms of the pancreas. Pathology and genetics of tumors of the digestive system. WHO classification of tumors of the digestive system. IARC Press, Lyon, France, pp. 231-233
49. Tseng JF, Warshaw AL, Sahani DV, Lauwers GY, Rattner DW, et al. (2005) Serous cystadenoma of the pancreas: Tumor growth rate and recommendations for treatment. Ann Surg 242(3): 413-421.

50. Papavramidis T, Papavramidis S (2005) Solid pseudopapillary tumors of the pancreas: Review of 718 patients reported in English literature. J Am Coll Surg 200(6): 965-972.

51. Yu PF, Hu ZH, Wang XB, Guo JM, Cheng XD, et al. (2010) Solid pseudopapillary tumor of the pancreas: A review of 553 cases in Chinese literature. World J Gastroenterol 16(10): 1209-1214.

52. Cantisani V, Mortele KJ, Levy A, Glickman JN, Ricci P, et al. (2003) MR imaging features of solid pseudopapillary tumor of the pancreas in adult and pediatric patients. Am J Roentgenol 181(2): 395- 401.

53. Yin Q Wang M, Wang C, Wu Z, Yuan F, et al. (2012) Differentiation between benign and malignant solid pseudopapillary tumor of the pancreas by MDCT. Eur J Radio 181(11): 3010-3018.

54. McCluney S, Wijesuriya N, Sheshappanavar V, Chin Aleong J, Feakins $\mathrm{R}$, et al. (2018) Solid pseudopapillary tumor of the pancreas: clinicopathological analysis. ANZ J Surg 88(9): 891-895.

55. Butte JM, Brennan MF, Gönen M, Tang LH, D’Angelica MI, et al. (2010) Solid pseudopapillary tumors of the pancreas. clinical features, surgical outcomes, and long-term survival in 45 consecutive patients from a single center. J Gastrointest Surg 15(2): 350-357.

56. Reddy S, Cameron JL, Scudiere J, Hruban RH, Fishman EK, et al. (2009) Surgical management of solid-pseudopapillary neoplasms of the pancreas (Franz or Hamoudi Tumors): a large single-institutional series. J Am Coll Surg 208(5): 950-957.

57. Kim Y, Cho JH (2015) Rare nonneoplastic cysts of pancreas. Clin Endosc 48(1): 31-38.

58. Sugiyama Y, Kawamoto T, Sasajima J, Koizumi K, Karasaki H, et al. (2016) A Rare Case of epidermoid cyst in the pancreatic tail invaginated from the splenic hilum: The long-term changes in the imaging findings. Intern Med 55(24): 3591-3594.

59. Oforia E, Ramaia D, Etiennea D, Reddya M, Shahzada G (2017) Large dermoid cyst presenting as recurrent pancreatitis. Gastroenterol Res 10(5): 322-324.

60. Adike A, Horsley Silva JL, Deval N, Conley CR, Lam Himlin DM (2016) An unusual suspect: Lymphoepithelial cyst of the pancreas. Case Rep Gastrointest Med 2016: 5492824.

61. Jani N, Hani MB, Schulick RD, Hruban R, Cunningham SC (2011) Diagnosis and management of cystic lesions of the pancreas. Diagnostic and Therapeutic Endoscopy 2011: 478913.

62. Fujii M, Saito H, Yoshioka M, Shiode J (2018) Rare case of pancreatic cystic lymphangioma. Intern Med 57(6): 813-817.

63. Lu T, Yang C (2015) Rare case of adult pancreatic hemangioma and review of the literature. World J Gastroenterol 21(30): 9228-9232.

64. Li Y, Dai M, Chang X, Hu W, Chen J, et al. (2016) Mixed serous neuroendocrine neoplasm of the pancreas. Case report and literature review. Medicine (Baltimore) 95(34): e4205.

65. Chia1 C, Pandya CJ, Kamalesh A, Shelat VG (2015) Splenic artery pseudoaneurysm masquerading as a pancreatic cyst-A diagnostic challenge. Int Surg 100(6): 1069-1071.

66. Doepker MP, Ahmad SA (2016) Gastric duplication cyst: A rare entity. J Surg Case Rep (5): 1-3.

67. Voudoukis E, Velegraki M, Khamaysi I, Karoumpalis I, Kazamias G, et al. (2018) Large adrenal cyst masquerading as a pancreatic cystic tumor: A rare diagnosis based on endoscopic ultrasound. Endoscopy International Open 6(9): E1109-E1111.

68. Dijck WP, Groot VP, Brosens LA, Hagendoorn J, Rinkes IB, et al. (2016) Rare case of an epithelial cyst in an intrapancreatic accessory spleen treated by robot-assisted spleen preserving distal pancreatectomy. Case Rep Gastrointest Med 2016: 2016. 
69. Fujii M, Yoshioka M, Shiode J (2016) Two cases of an epidermoid cyst developing in an intrapancreatic accessory spleen identified during laparoscopic distal pancreatectomy. Intern Med 55(21): 3137-3141.

70. Zhou RX, Hu HJ, Ma WJ, Jiang Y, Li FY (2018) Alveolar echinococcosis in the head of pancreas. Medicine (Baltimore) 97:11(e0072).

71. Koh YX, Chok AY, Zheng HL, Tan CS, Goh BK (2014) A systematic review and metaanalysis of the clinicopathologic characteristics of cystic versus solid pancreatic neuroendocrine neoplasms. Surgery 156(1): 83-96.

72. Hurtado Pardo L, A Cienfuegos J, Ruiz Canela M, Panadero P, Benito A, et al. (2017) Cystic pancreatic neuroendocrine tumors (cPNETs): A systematic review and meta-analysis of case series. Rev Esp Enferm Dig 109(11): 778-787.

73. Caglià P, Cannizzaro MT, Tracia A, Amodeo L, Tracia L, et al. (2015) Cystic pancreatic neuroendocrine tumors: To date a diagnostic challenge. Int J Surg 21(Suppl 1): S44-S49.

74. Bordeianou L, Vagefi PA, Sahani D, Deshpande V, Rakhlin E, et al. (2008) Cystic pancreatic endocrine neoplasms: A distinct tumor type? J Am Coll Surg 206(6): 1154-1158.

75. Dąbkowski K, Kos Kudł B, Andrysiak Mamos E, Syrenicz A, Pilch Kowalczyk J, et al. (2018) Cystic pancreatic neuroendocrine tumors - a gastroenterologist's point of view. Endokrynol Pol 69(3): 320-325.

76. Kawamoto S, Johnson PT, Shi C, Singhi AD, Hruban RH, et al. (2013) Pancreatic neuroendocrine tumor with cystlike changes: Evaluation with MDCT. Am J Roentgenol 200(3): W283-W290.

77. Sureka B, Bihari C, Arora A, Agrawal N, Bharathy KGS, et al. (2017) Imaging paradigm of cystic lesions in pancreas. JOP 17(5).

78. Ottenhof NA, Milne AN, Morsink FH, Drillenburg P, Ten Kate FJ, et al. (2009) Pancreatic intraepithelial neoplasia and pancreatic tumorigenesis of mice and men. Arch Pathol Lab Med 133(3): 375-381.

79. Pusateri AJ, Krishna SG (2018) Pancreatic Cystic Lesions: Pathogenesis and Malignant Potential. Diseases 6(2): E50.

80. Adsay NV, Longnecker DS, Klimstra DS (2000) Pancreatic tumors with cystic dilatation of the ducts: Intraductal papillary mucinous neoplasms and intraductaloncocytic papillary neoplasms. Semin Diagn Pathol 17(1): 16-30

81. Distler M, Kersting S, Niedergethmann M, Aust DE, Franz M, et al. (2013) Pathohistological subtype predicts survival in patients with intraductal papillary mucinous neoplasm (IPMN) of the pancreas. Ann Surg 258(2): 324-330.

82. The International Agency for Research on Cancer (2010) WHO classification of tumors of the digestive system. In: Bosman FT (Eds.), ( $4^{\text {th }}$ Edn), Medicine, Lyon, France.

83. Basturk O, Hong SM, Wood LD, Adsay NV, Albores Saavedra J, et al. (2015) A Revised classification system and recommendations from the baltimore consensus meeting for neoplastic precursor lesions in the pancreas. Am J Surg Pathol 39(12): 1730-1741.

84. Furukawa T, Hatori T, Fujita, Yamamoto M, Kobayashi M, et al. (2011) Prognostic relevance of morphological types of intraductal papillary mucinous neoplasms of the pancreas. Gut 60(4): 509-516.

85. Grützmann R, Niedergethmann M, Pilarsky C, Klöppel G, Saeger HD (2010) Intraductal papillary mucinous tumors of the pancreas: Biology, diagnosis, and treatment. Oncologist 15(12): 1294-1309.

86. Koh YX, Zheng HL, Chok AY, Tan CS, Wyone W, et al. (2015) Systematic review and meta-analysis of the spectrum and outcomes of different histologic subtypes of noninvasive and invasive intraductal papillary mucinous neoplasms. Surgery 157(3): 496-509.

87. Baker ML, Seeley ES, Pai R, Suriawinata AA, Mino Kenudson M, et al. (2012) Invasive mucinous cystic neoplasms of the pancreas. Experimental and Molecular Pathology 93(3): 345-349.

88. Bai X, Ye L, Zhang Q, Prasoon P, Wang J, et al. (2014) Surgical resection and outcome of pancreatic cystic neoplasms in China: Analysis of a 16year experience from a single high-volume academic institution. World J Surg Oncol 12: 228.

89. Jang KT, Park SM, Basturk O, Bagci P, Bandyopadhyay S, et al. (2015) Clinicopathologic characteristics of 29 invasive carcinomas arising in 178 pancreatic mucinous cystic neoplasms with ovarian-type stroma: Implications for management and prognosis. Am J Surg. Pathol 39(2): 179-187.

90. Adsay NV, Fukushima N, Furukawa T, Hruban RH, Klimstra DS, et al. (2010) Intraductal neoplasm of the pancreas. In: Bosman FT, et al. (Eds.), WHO classification of tumors of digestive system. WHO Press, Lyon, France, pp. 304-313.

91. Strobel O, Z'graggen K, Schmitz Winnenthal FH, Friess H, Kappeler A, et al. (2003) Risk of malignancy in serous cystic neoplasms of the pancreas. Digestion 68(1): 24-33.

92. George DH, Murphy F, Michalski R, Ulmer BG (1989) Serous cystadenocarcinoma of the pancreas: A new entity? Am J Surg Pathol 13(1): 61-66.

93. Kamei K, Funabiki T, Ochiai M, Amano H, Kasahara M, et al. (1991) Multifocal pancreatic serous cystadenoma with atypical cells and focal perineural invasion. Int J Pancreatol 10(2): 161-172.

94. Yoshimi N, Sugie S, Tanaka T, Aijin W, Bunai Y, et al. (1992) A rare case of serous cystadenocarcinoma of the pancreas. Cancer 69(10): 2449-2453.

95. Ohta T, Nagakawa T, Itoh H, Fonseca L, Miyazaki I, et al. (1993) A case of serous cystadenoma of the pancreas with focal malignant changes. Int ] Pancreatol 14(3): 283-289.

96. Widmaier U, Mattfekdt T, Siech M, Beger HG (1996) Serous cystadenocarcinoma of the pancreas. Int J Pancreatol 20(2): 135-139.

97. Eriguchi N, Aoyagi S, Nakayama T, Hara M, Miyazaki T, et al. (1998) Serous cystadenocarcinoma of the pancreas with liver metastases. J Hepatobiliary Pancreat Surg 5(4): 467-470.

98. Abe H, Kubota K, Mori M, Miki K, Minagawa M, et al. (1998) Serous cystadenoma of the pancreas with invasive growth: Benign or malignant? Am J Gastroenterol 93(10): 1963-1966.

99. Shintaku M, Arimoto A, Sakita N (2005) Serous cystadenocarcinoma of the pancreas. Pathol Int 55(7): 573-580.

100. Matsumoto T, Hirano S, Yada K, Shibata K, Sasaki A, et al. (2005) Malignant serous cystic neoplasm of the pancreas: Report of a case and review of the literature. J Clin Gastroenterol 39(3): 253-256.

101. Friebe V, Keck T, Mattern D, Schmitt Graeff A, Werner M, et al. (2005) Serous cystadenocarcinoma of the pancreas: Management of a rare entity. Pancreas 31(2): 182-187.

102. Hruban RH, Klimstra DS, Pitman MB (2006) Atlas of tumor pathology. Tumors of the Pancreas. $4^{\text {th }}$ series. American Institute of Pancreatology, Washington, USA, ( $6^{\text {th }}$ Edn), pp. 45-47.

103. Galanis C, Zamani A, Cameron JL, Campbell KA, Lillemoe KD, et al (2007) Resected serous cystic neoplasms of the pancreas: a review of 158 patients with recommendations for treatment. J GastrointestSurg 11(7): 820-826.

104. Khashab MA, Shin EJ, Amateau S, Canto MI, Hruban RH, et al. (2011) Tumor size and location correlate with behavior of pancreatic serous cystic neoplasms. Am J Gastroenterol106(8): 1521-1526.

105. Tipton SG, Smyrk TC, Sarr MG, Thompson GB (2006) Malignant potential of solid pseudopapillary neoplasm of the pancreas. Br J Surg 93(6): 733-737.

106. Chiang AL, Lee LS (2016) Clinical approach to incidental pancreatic cysts. World J Gastroenterol 22(3): 1236-1245.

107. Martin RCG, Klimstra DS, Brennan MF, Conlon KC (2002) Solidpseudopapillary tumor of the pancreas: A surgical enigma? Ann Surg Oncol 9(1): 35-40. 
108. Chang MK, Kyung SK, Jin SC, Kim H, Woo JL, et al. (2006) Solid pseudopapillary tumor of the pancreas suggesting malignant potential. Pancreas 32(3): 276-280.

109. Kawamoto S, Lawler LP, Horton KM, Eng J, Hruban RH, et al. (2006) MDCT of intraductal papillary mucinous neoplasm of the pancreas: evaluation of features predictive of invasive carcinoma. AJR Am J Roentgenol 186(3): 687-695.

110. Curry CA, Eng J, Horton KM, Urban B, Siegelman S, et al. (2000) CT of primary cystic pancreatic neoplasms: Can CT be used for patient triage and treatment? AJR Am J Roentgenol 175(1): 99-103.

111. Berland LL, Silverman SG, Gore RM, Mayo Smith WW, Megibow AJ, et al. (2010) Managing incidental findings on abdominal CT: White paper of the ACR incidental findings committee. J Am Col Radiol 7(10): 754773.

112. Sainani NI, Saokar A, Deshpande V, Fernandez del Castillo C, Hahn P, et al. (2009) Comparative performance of MDCT and MRI with MR cholangiopancreatography in characterizing small pancreatic cysts. Am J Roentgenol 193(3): 722-731.

113. Nakagawa A, Yamaguchi T,Ohtsuka M, Ishihara T, Sudo K, et al. (2009) Usefulness of multidetector computed tomography for detecting protruding lesions in intraductal papillary mucinous neoplasm of the pancreas in comparison with single-detector computed tomography and endoscopic ultrasonography. Pancreas 38(2): 131-136.

114. Kamata K, Kitano M, Omoto S, Kadosaka K, Miyata T, et al. (2016) Contrast-enhanced harmonic endoscopic ultrasonography for differential diagnosis of pancreatic cysts. Endoscopy 48(1): 35-41

115. Harima H, Kaino S, Shinoda S, Kawano M, Suenaga S, et al. (2015) Differential diagnosis of benign and malignant branch duct intraductal papillary mucinous neoplasm using contrast-enhanced endoscopic ultrasonography. World J Gastroenterol 21(20): 6252-6260.

116. Bassi C, Salvia R, Gumbs AA, Butturini G, Falconi M, et al. (2002) The value of standard serum tumor markers in differentiating mucinous from serous cystic tumors of the pancreas: CEA, Ca 19-9, Ca 125, Ca 15-3. Langenbecks Arch Surg 387(7-8): 281-285.

117. Ohno E, Hirooka Y, Itoh A, Ishigami M, Katano Y, et al. (2009) Intraductal papillary mucinous neoplasms of the pancreas: differentiation of malignant and benign tumors by endoscopic ultrasonography findings of mural nodules. Ann Surg 249(4): 628-634.
118. Hirooka Y, Goto H, Itoh A, Hashimoto S, Niwa K, et al. (2003) Case of intraductal papillary mucinous tumor in which endosonographyguided fine-needle aspiration biopsy caused dissemination. J Gastroenterol Hepatol 18(11): 1323-1324.

119. Yamabe A, Irisawa A, Shibukawa G, Hoshi K, Fujisawa M, et al. (2016) Rare condition of needle tract seeding after EUS-guided FNA for intraductal papillary mucinous carcinoma. EndoscInt Open 4(7): E756-E758.

120. Minaga K, Takenaka M, Katanuma A, Kitano M, Yamashita Y, et al. (2017) Needle tract seeding: An overlooked rare complication of endoscopic ultrasound-guided fine-needle aspiration. Oncology 93(suppl 1): 107112.

121. Levy MJ, Gleeson FC, Campion MB, Caudill JL, Clain JE, et al. (2010) Prospective cytological assessment of gastrointestinal luminal fluid acquired during EUS: a potential source of false-positive FNA and needle tract seeding. Am J Gastroenterol 105(6): 1311-1318.

122. Jenssen C, Kahl S (2015) Management of incidental pancreatic cystic lesions. Viszeral medizin 31(1): 14-24.

123. Spence RJ, Dasari B, Love M, Kelly B, Taylor M (2011) Overview of the investigation and management of cystic neoplasms of the pancreas. Dig Surg 28:386-397.

124. Giovannini M (2015) Needle-based confocal laser endomicroscopy. Endosc Ultrasound 4:284-8.

125. Konda VJ, Meining A, Jamil LH, Giovannini M, Hwang JH, et al. (2013). A pilot study of in vivo identification of pancreatic cystic neoplasms with needle-based confocal laser endomicroscopy under endosonographic guidance. Endoscopy 45: 1006-1013.

1. 126. Baiocchi GL, Portolani N, Bertagna F, Gheza F, Pizzocaro C, et al (2008) Possible additional value of 18FDG-PET in managing pancreas intraductal papillary mucinous neoplasms: preliminary results. J Exp Clin Cancer Res 27: 1

126. Pedrazzoli S, Sperti C, Pasquali C, Bissoli S, Chierichetti F (2011) Comparison of International Consensus Guidelines versus 18-FDG PET in detecting malignancy of intraductal papillary mucinous neoplasms of the pancreas. Ann surg 254(6): 971-976.

127. Gonzalez Obeso E, Murphy E, Brugge W, Deshpande V (2009) Pseudocyst of the pancreas: The role of cytology and special stains for mucin. Cancer 117(2): 101-107.
Creative Commons Attribution 4.0 International License

For possible submissions Click Here

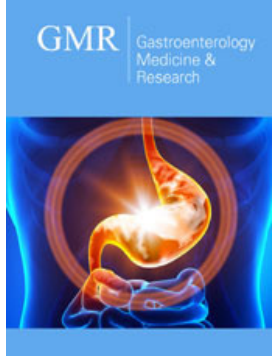

\section{Gastroenterology Medicine \& Research}

\section{Benefits of Publishing with us}

- High-level peer review and editorial services

- Freely accessible online immediately upon publication

- Authors retain the copyright to their work

- Licensing it under a Creative Commons license

- Visibility through different online platforms 